\title{
STRUCTURAL EVALUATION AND MAINTENANCE OF BROOKS AQUEDUCT HISTORIC SITE
}

\author{
ALIREZA ROUHI ${ }^{1}$, NIGEL G. SHRIVE ${ }^{2 *}$ \\ ${ }^{1 \& 2}$ University of Calgary, Schulich School of Engineering \\ 622 Collegiate P1 NW, Calgary, AB, CANADA T2N 4V8 \\ e-mail: alireza.rouhi@ucalgary.ca, \\ email: ngshrive@ucalgary.ca, www.ucalgary.ca (*corresponding author)
}

Keywords: Reinforced Concrete, Aqueduct, Structural Evaluation, Durability, Numerical Modeling, Damage

Abstract. Brooks Aqueduct in Alberta, Canada is one of the largest and most sophisticated reinforced concrete aqueducts in the world. Now a national historic site, Brooks Aqueduct was built in 1914. The structure suffers from cracking and degradation in certain locations. To find out the possible main causes of potential overstress and damage in the different areas of the structure, it was evaluated by site inspections, some laboratory tests and analyzed numerically using Abaqus finite element software. Results of the numerical analysis are compared with the inspection and testing results and conclusions are made about the causes of deterioration and ways to conserve and repair the structure.

\section{INTRODUCTION}

Brooks Aqueduct is a $3.2 \mathrm{~km}$ long elevated flume built by the Canadian Pacific Railway (CPR) near the city of Brooks in southeast Alberta, Canada. The aqueduct was constructed to supply water to irrigate 50,000 hectares of land, and thus had a significant effect on the economy of that region for a long time.

The concrete in the aqueduct was subject to significant damage and deterioration almost from the beginning of operation. The damage was mostly because of the poor quality of the concrete with respect to durability issues, poor design and a lack of proper workmanship, all stemming from the paucity of knowledge about these issues at the time of construction.

To address the problems and issues of the aqueduct, and to maintain the structure in a safe condition for the public to view, several assessments have been performed on the structure over the last few years. We used the results of past field and laboratory tests (such as concrete cover measurements, carbonation depths, corrosion potentials, areas of delamination, concrete and rebar strength, air void analysis and petrographic analysis) to develop a 3-D finite element model of the aqueduct using Abaqus software. Both the concrete and the steel reinforcement are modelled with the software.

\section{HISTORY AND SIGNIFICANCE}

The aqueduct (Figure 1) had a noticeable role in the CPR's efforts to settle Western Canada and played an important role in the growth of farming establishments in southeast Alberta. The 
aqueduct was commissioned in 1914 to transfer water at a volume of 25.5 cubic meters per second over a valley $3.2 \mathrm{~km}$ wide and $20 \mathrm{~m}$ deep [1]. The Eastern Irrigation District operated and maintained the aqueduct after 1935.

The flume is a shell (as seen in Figure 1) in the shape of a "hydrostatic catenary". This geometric shape is supposed to place the flume under direct axial tension with no moment or shear when the flume is filled to the design level.

The aqueduct was abandoned in 1979 after 65 years of service and was replaced with a larger earthen canal built to the south of the aqueduct. Brooks Aqueduct is a nationally significant civil engineering achievement because of its design, materials, and large size. The Canadian Society for Civil Engineering named Brooks Aqueduct as a National Historic Civil Engineering Site in 2000 [1][2]. An interpretative centre has been constructed and a part of the aqueduct has been removed to improve access for the public. More than $3 \mathrm{~km}$ still remains with various problems in terms of cracking and spalling of the concrete, and some sections of the flume missing patches of concrete.

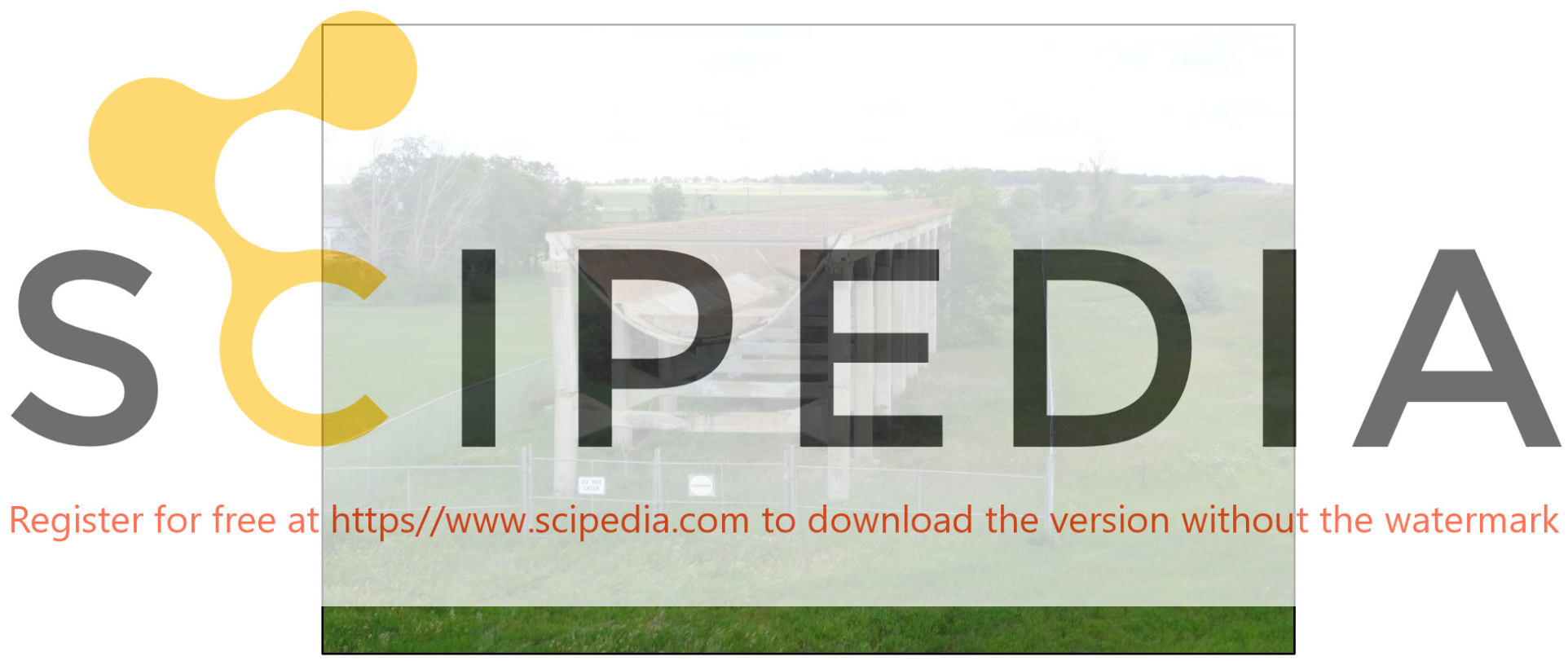

Figure 1: A view of Brooks Aqueduct

\section{CONSTRUCTION}

Construction of the aqueduct (Figure 2) allowed the irrigation of a region of Southern Alberta called "the Eastern Irrigation District". It is a remarkable product of Canadian engineering and one of the largest aqueducts of its kind in the world [1]. Brooks Aqueduct would be considered a significant construction project even on today's scales. Despite the flaws that have been observed during its century of existence, the people who built this structure deserve high respect for their innovation and work [1]. 


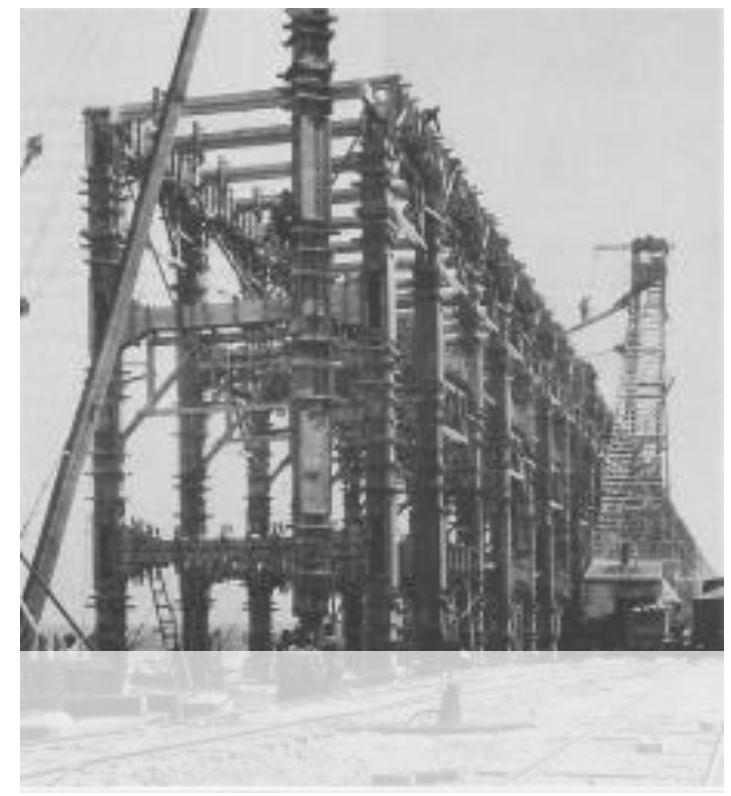

Figure 2 : Superstructure forms for Brooks Aqueduct, July 18, 1914 [1]

\section{EARLY REPAIRS AND PROBLEMS}

The concrete in the aqueduct has been subject to significant damage and deterioration since the early stages of operation (4.g.: Figure 3). The damage is mainly due to a lack of do from issues unknown at the time of construction. Some of the nost critical issues water-cement ratio, lack of freeze-thaw resistance (air-entrainment), lack of proper
the steel, lack of pre-stressing of the concrete in tension areas such as the flume, inc in the placement of rebars, alkali-silica reaction of the concret in contact with the soil, lack of rebars in the footings, and poor grading of the aggregates (by today's standards) [3].

Register for free at https//www.scipedia.com to download the version without the watermark

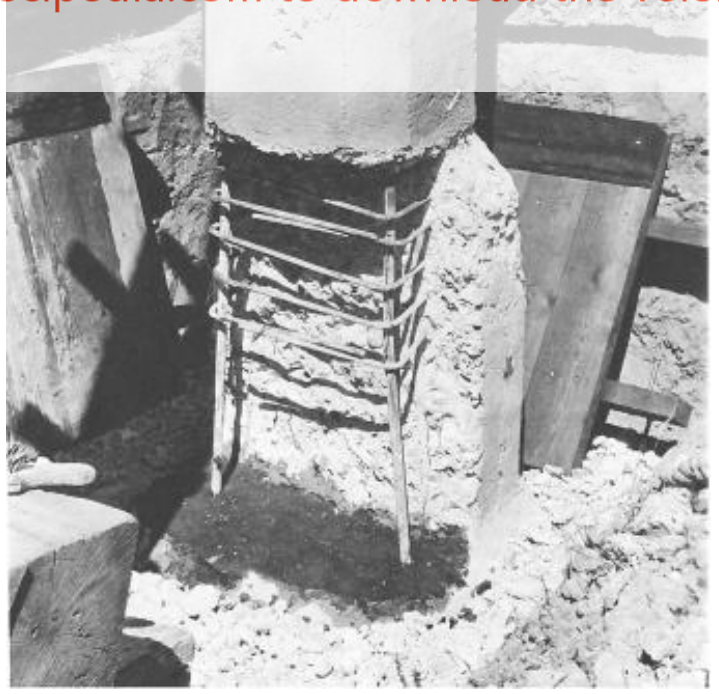

Figure 3 : Repair of footing -1927 [3] 
To address the problems being faced in the conservation and repair of the aqueduct adequately, the leading causes of damage and deterioration of the structure have to be identified. Repair and conservation options then have to be investigated. The structure was under repair pretty much constantly from the early days of operation, due to its design flaws [3]. Lots of problems occurred near the expansion joints due to water leakage. Some of these repairs are documented and branded with date stamps on-site, but unfortunately, complete registration of repair works during the long period of its service life and subsequently does not exist. Table 1 shows a summary of different damage types, the severity of the damage, and the approximate time of their first recorded repair.

Table 1 : Recorded damages and repairs of the aqueduct [3][4]

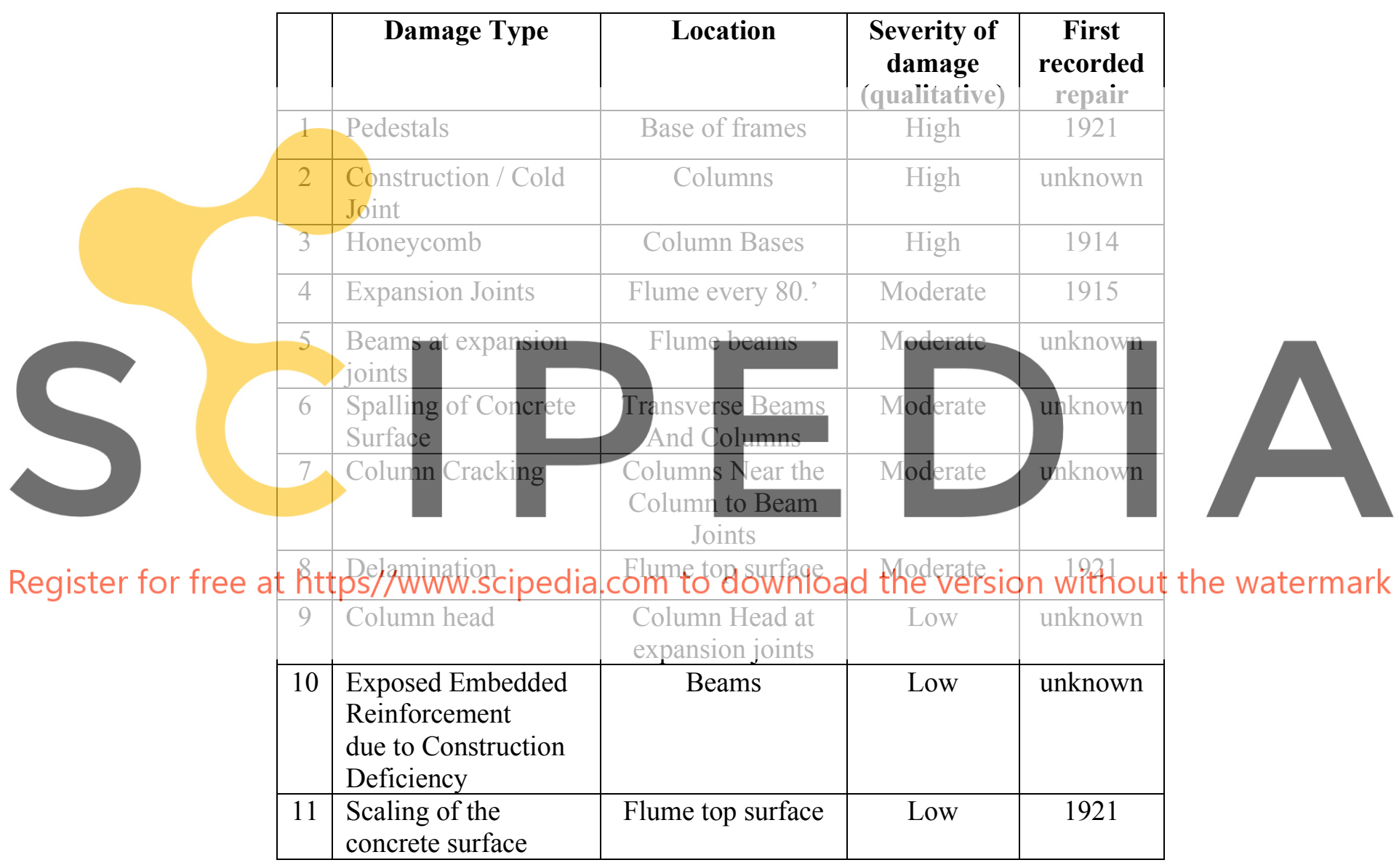

\section{PREVIOUS CONDITION ASSESSMENTS}

To address the problems and issues of the aqueduct, and to maintain the structure in a safe condition, several assessments have been performed on the structure. The first available condition assessment was performed by a structural engineering company in 2006 and consists only of visual evaluation [4]. Another set of field and laboratory tests were performed on the Brooks Aqueduct in 2016, and a summary of the results of these tests is shown in Table 2 [5]. The results of these tests were used in the structural analysis of the aqueduct. 
Table 2 : Concrete and steel test results of Brooks Aqueduct [5]

\begin{tabular}{|l|c|c|}
\hline Average Values & Flume & Bent \\
\hline Concrete Cover (mm) & 33 & 73 \\
\hline $\begin{array}{l}\text { Carbonation Depth } \\
(\mathrm{mm})\end{array}$ & 28 & 62 \\
\hline $\begin{array}{l}\text { Delamination (\% of } \\
\text { Area) }\end{array}$ & 34 & 14 \\
\hline $\begin{array}{l}\text { Rebar Yield Strength } \\
(\mathrm{MPa})\end{array}$ & N/A & 293 \\
\hline $\begin{array}{l}\text { Rebar Tensile } \\
\text { Strength (MPa) }\end{array}$ & N/A & 446 \\
\hline $\begin{array}{l}\text { Concrete Strength } \\
(\text { MPa })\end{array}$ & N/A & Minor ASR \\
\hline \begin{tabular}{l} 
Petrographic Analysis \\
\hline
\end{tabular}
\end{tabular}

\section{FINITE ELEMENT MODEL OF THE AQUEDUCT}

A finite element model using Abaqus software [6] was made to assess the behaviour of the structure under loading and environmental effects. Given the three-dimensional nature of the concrete members, eight-node continuum elements (C3D8) were used to model the concrete.

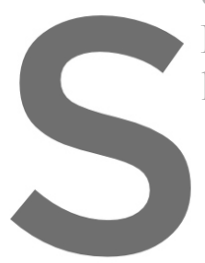
Parameters used
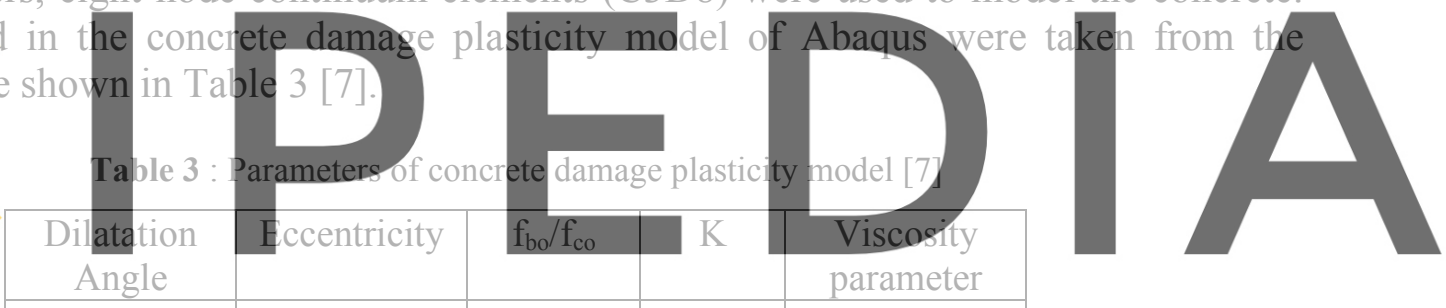

Register for free at https//wWw.scipedia.com to download the version without the watermark

Two-dimensional truss elements (T3D2) were used to model the steel reinforcing bars, as these elements were proved to be efficient for modelling tensile forces and stresses. The truss elements were coupled to the C3D8 concrete elements using the "embedded regions" function of Abaqus. This function is commonly used to model reinforcement of concrete in Abaqus and constrains the displacements of the nodes of the reinforcing bars (truss elements) to the displacements of the neighbouring nodes of the concrete (solid elements) in which the bars are embedded [6][8]. The steel reinforcement was modelled as elastic-perfectly plastic material, with a yield stress of $240 \mathrm{MPa}$, to be conservative, according to the results of the tension tests on actual bars and the availability of material at the time of construction of the aqueduct.

A section of the aqueduct between movement joints was analyzed under what was considered normal loading conditions and a series of different effects to determine if any environmental or time-dependent effect could cause some of the observed cracking.

\section{RESULTS OF ANALYSIS UNDER NORMAL CONDITIONS}

The finite element model of the aqueduct was analyzed under normal loading conditions which consisted of the self-weight of the structure and the flume full of water (or snow). The 
maximum principal stresses in the concrete are shown in Figure 4. The maximum compressive stress is $4.02 \mathrm{MPa}$, while the maximum tensile stress was found to be $0.58 \mathrm{MPa}$ : both of these stresses are well below the strength of the concrete. Principal stresses in the flume and column caps are shown in Figure 4.

Axial stresses in the rebars are presented in Figure 5. The maximum rebar tensile stress is $140 \mathrm{MPa}$, and the maximum compressive rebar stress is $28 \mathrm{MPa}$ which are also well below the yield strength of the reinforcement.
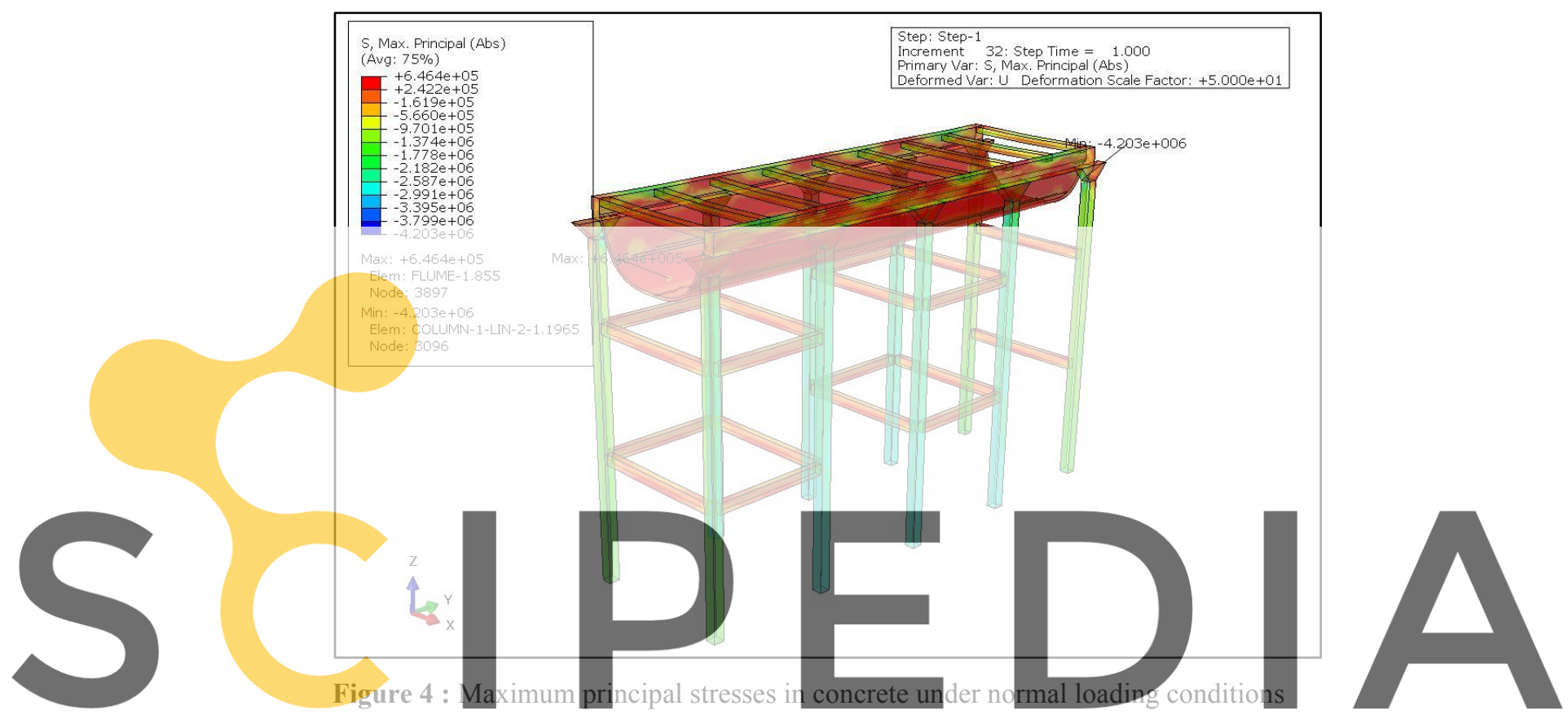

Register for free at https//www.scipedia.com to download the version without the watermark
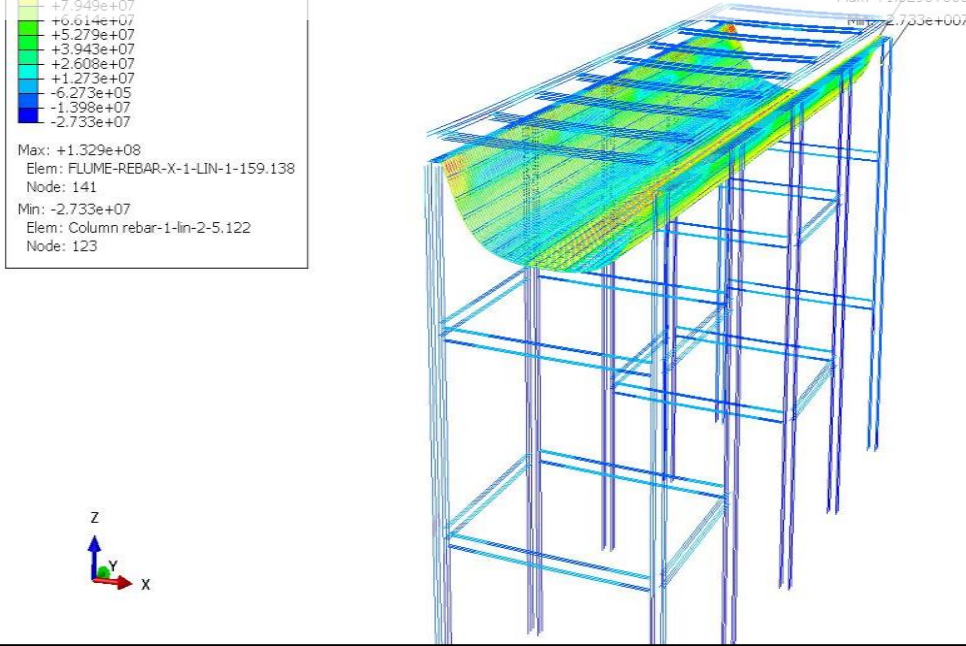

Figure 5 : Maximum principal stresses in rebars under normal loading conditions 


\section{EFFECT OF A POSSIBLE SETTLEMENT OF ONE COLUMN}

Differential settlement under one column can happen due to local poor soil conditions. This kind of settlement would induce displacements and stresses, and possibly cause damage to the structure. To evaluate the effect of such possible settlement on the structure, a $50 \mathrm{~mm}$ downward displacement was applied to each of the five columns on one side of the flume in turn. Because of the symmetry of the structure along the longitudinal centerline of the flume, the effect of the settlement of the columns on the other side of the flume will be the same. Results of the analysis due to the settlement at one column are shown in Figure 6 and Figure 7. The results show that except for very local areas due to the concentration of stresses in very small elements, the compressive and tensile stresses in the structure are well below levels that would cause damage despite imposing such a big and unusual settlement.
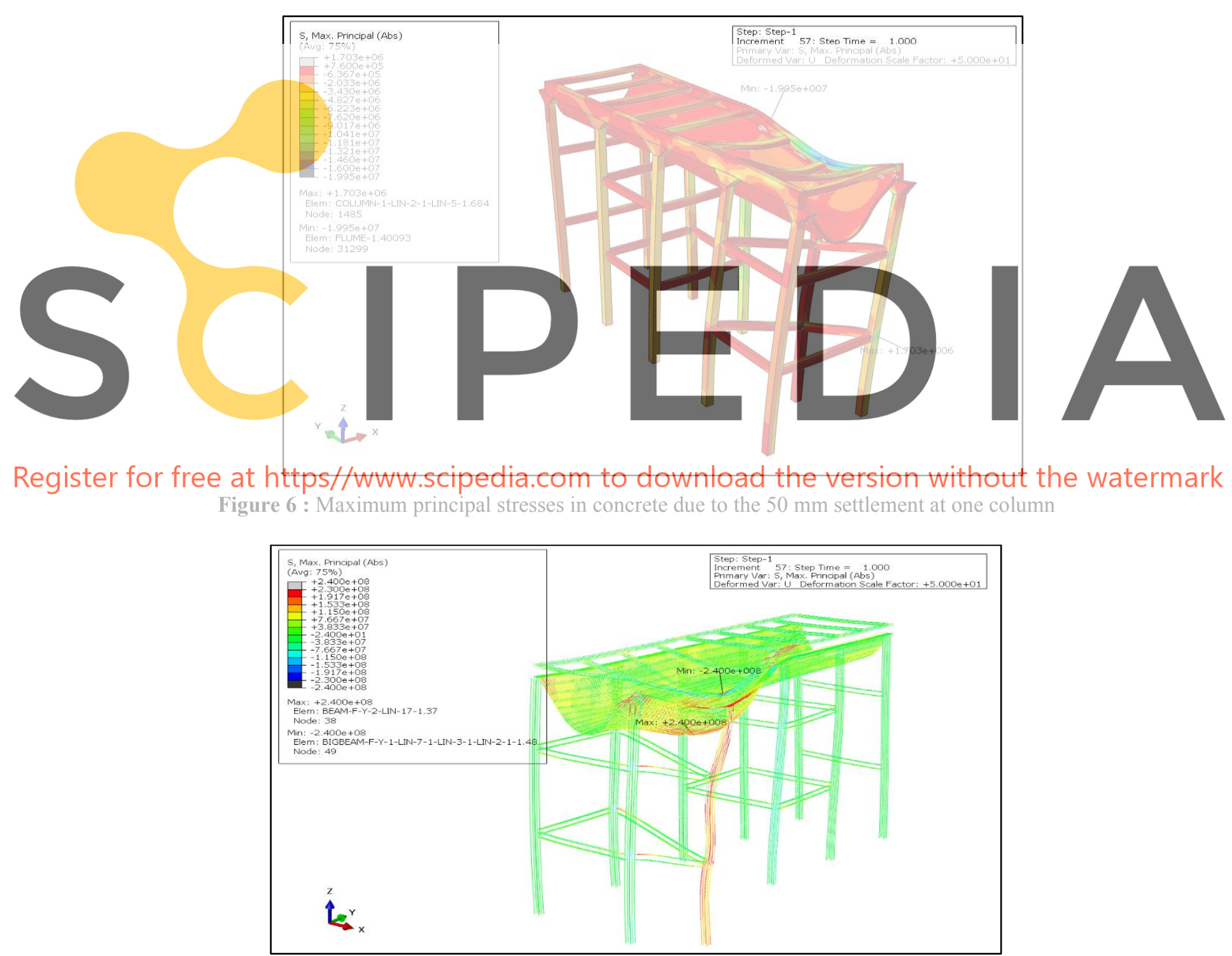

Figure 7 : Maximum principal stresses in rebars due to the $50 \mathrm{~mm}$ settlement at one column 


\section{EFFECT OF TIME-DEPENDENT RELATIVE SETTLEMENT AT ONE SIDE}

Creep in concrete is defined as an increase in strain in the concrete under sustained load. The creep rate is higher at higher temperatures and is accelerated with rapid heating as well as fast cooling. In the case of Brooks Aqueduct, the aqueduct has an east-west alignment, so the south side is exposed to more sun than the north side and is therefore subject to higher temperatures and less humidity than the north side. This is obvious from the extensive amount of lichen on the north side where more moist conditions exist, and the lack of lichen on the south side of the aqueduct (Figure 8). A possible effect of this situation is differential creep between the north and south columns of the aqueduct. This case was studied by imposing a $25 \mathrm{~mm}$ relative movement on the south side of the structure to represent the shortening of columns due to differential creep. The results of this analysis are shown in Figure 9 and Figure 10.
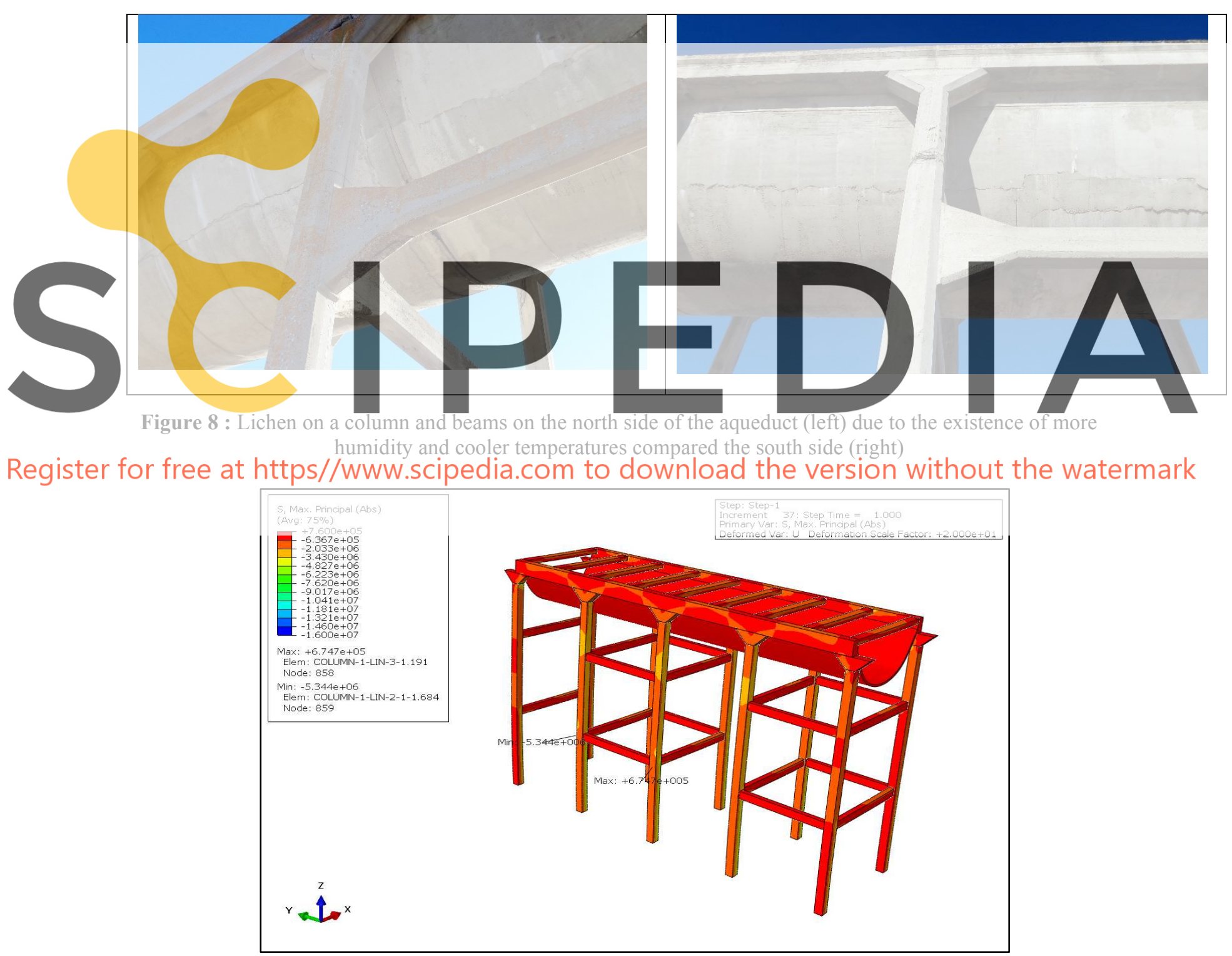

Figure 9 : Max. principal stresses in concrete due to settlement in all south columns 


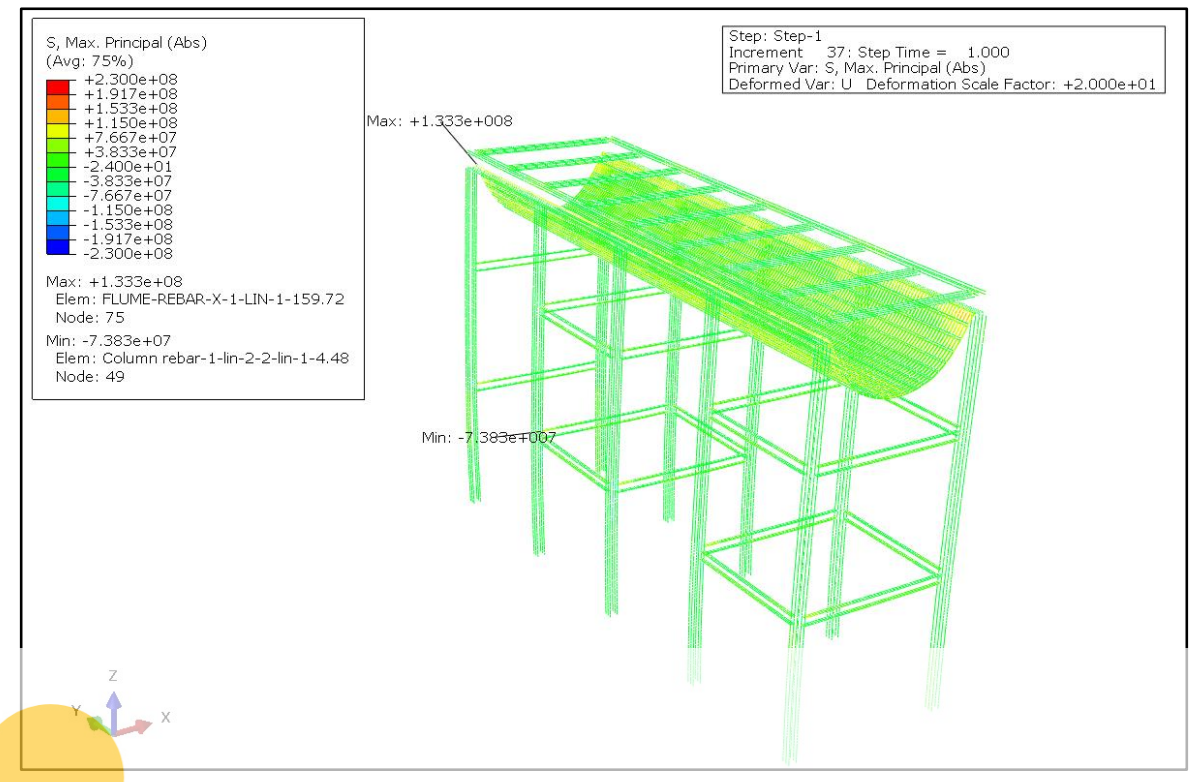

Figure 10 : Max. principal stresses in rebars due to settlement in all south columns

\section{OVERALL RESULTS OF ANALYSIS}

A summary of the results of the finite element analyses of the structure under different

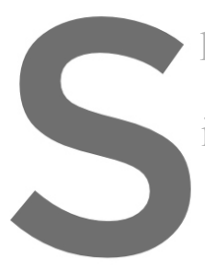

possible loading and environnental conditions are as follows:

1- The maximum stresses due to thermal loading are 15 MPa in conpression a in tension which occurs in small areas due to stress concentration.

2- The location of higher stresses are not where most of the damage and deterio

Based on the results of the analyses and comparing the results with the site inspections, it can be concluded that the most probable cause of deterioration of the concrete near the

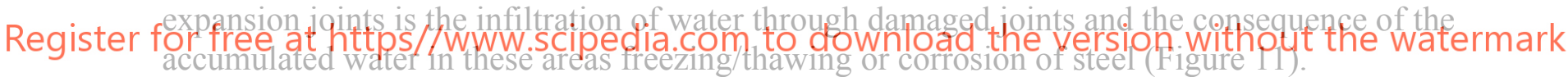
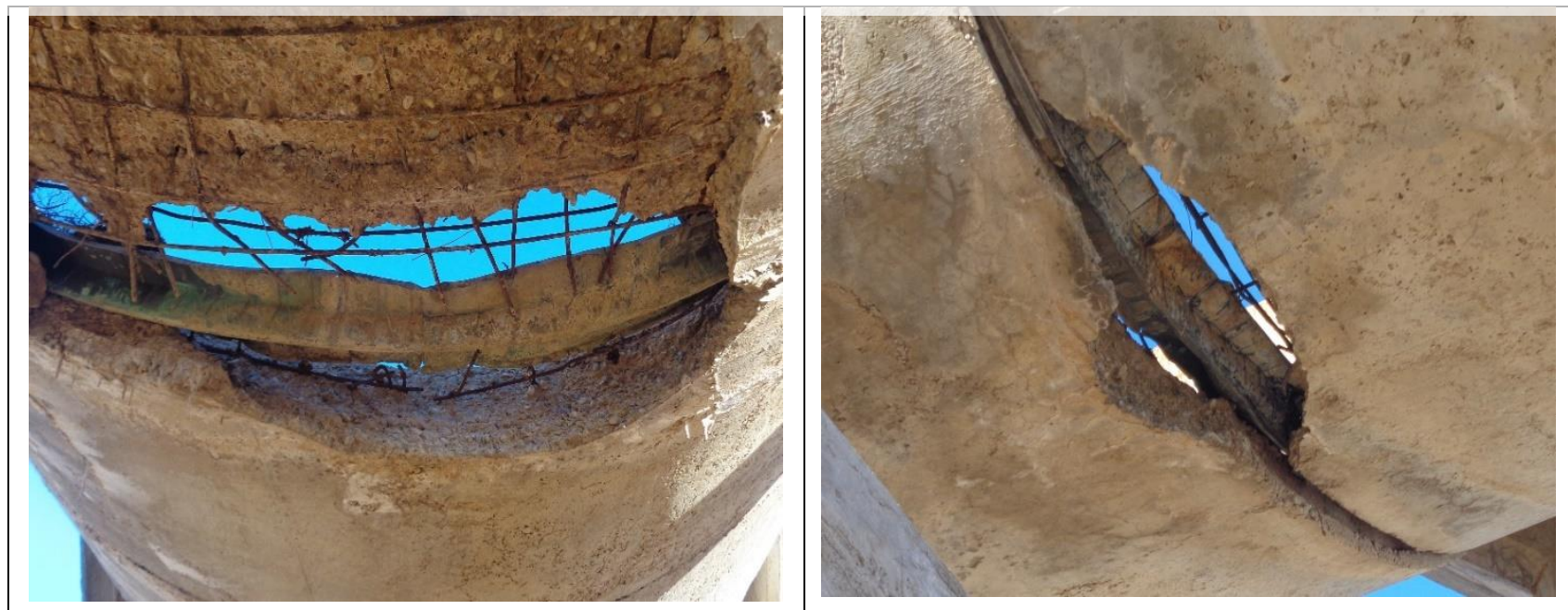

Figure 11 : Deterioration of flume at expansion joints 
Corrosion of steel could have happened due to lack of adequate concrete cover, poor quality of concrete and poor workmanship in proper placement of the rebars in the concrete according to drawings and specifications. As shown in Figure 12, in some places, the reinforcing bars were placed at the edge of the concrete formwork and thus had little or no cover which makes them very vulnerable to corrosion and deterioration. Damage and deterioration of longitudinal beams at expansion joints are also shown in Figure 13.

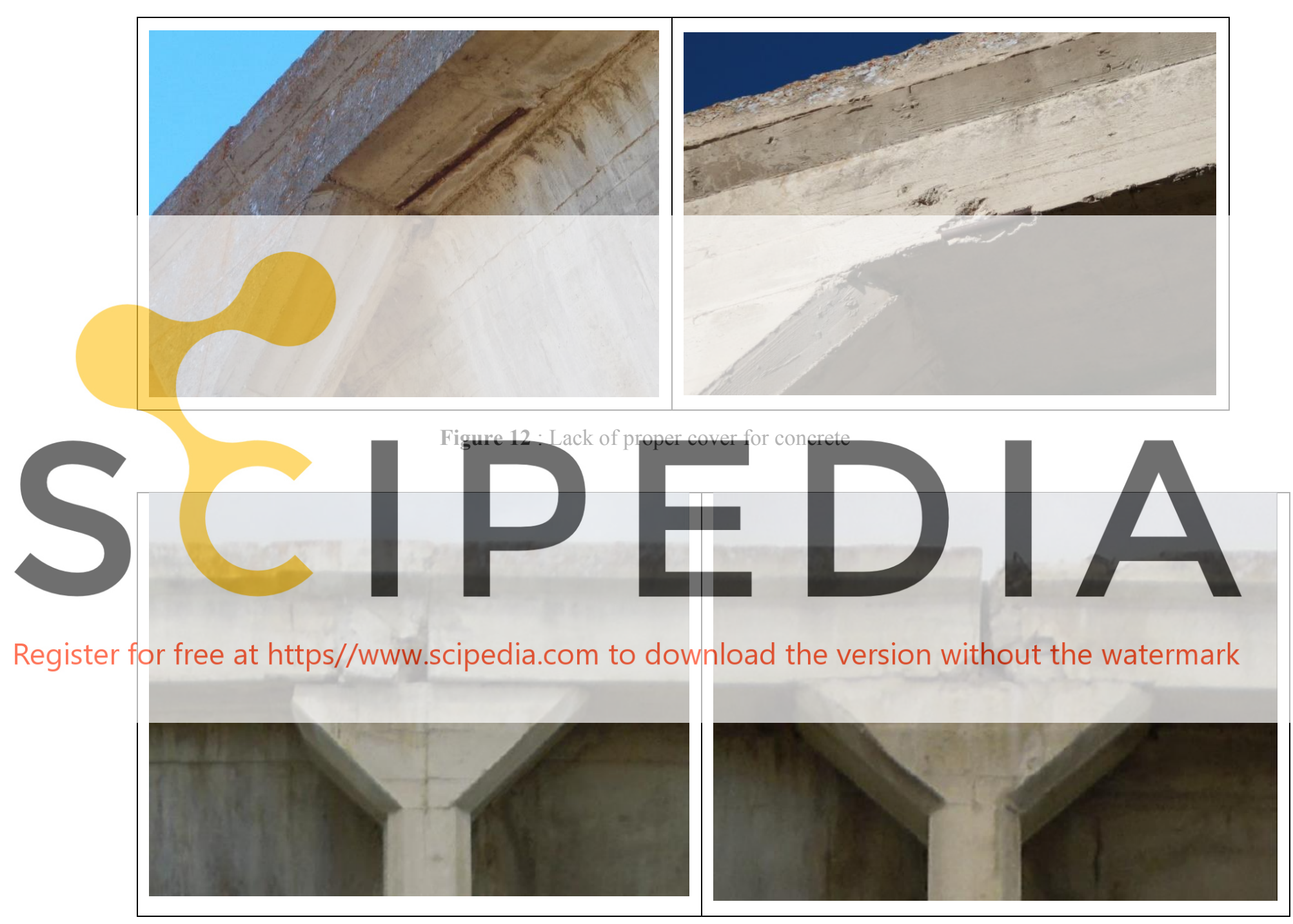

Figure 13 : Deterioration of longitudinal beams near expansion joints

\section{SELECTION CRITERIA FOR REPAIR MATERIALS}

One of the most common methods in the preservation of concrete structures is to use patch repairs in the areas that concrete is damaged or lost due to spalling or degradation. In the past, patch repairs were usually done based on the availability of material and the experience of the contractor: little attention was paid to the compatibility of the patch material with the existing materials in the structure. Unsuccessful repairs of the aqueduct in the past also highlight the 
importance of selecting the proper materials and methods of restoration.

Some research has been performed on the selection criteria for the repair material, and a summary of patch repair selection criteria for structural compatibility is shown in Table 4.

Table 4 : General requirements for patch repair material [9]

\begin{tabular}{|l|c|}
\hline \multicolumn{1}{|c|}{ Property } & $\begin{array}{c}\text { Repair mortar (R) vs existing } \\
\text { concrete (C) }\end{array}$ \\
\hline $\begin{array}{l}\text { Compressive, tensile and } \\
\text { flexural strength }\end{array}$ & $\mathrm{R} \geq \mathrm{C}$ \\
\hline Modulus of elasticity & $\mathrm{R} \geq \mathrm{C}$ \\
\hline $\begin{array}{l}\text { The coefficient of thermal } \\
\text { expansion }\end{array}$ & $\mathrm{R} \approx \mathrm{C}$ \\
\hline Adhesion in tension and shear & $\mathrm{R} \geq \mathrm{C}$ \\
\hline $\begin{array}{l}\text { Curing and long term } \\
\text { shrinkage }\end{array}$ & $\mathrm{R} \geq \mathrm{C}$ \\
\hline Fatigue performance & $\mathrm{R} \geq \mathrm{C}$ \\
\hline Poisson's ration & Depends on the type of repair \\
\hline Creep & $\begin{array}{l}\text { Depends on the desirable or } \\
\text { undesirable effect of creep }\end{array}$ \\
\hline
\end{tabular}

\section{CONCLUSIONS}

Based on the results of numerical models, visual site assessments, historical reports and laboratory tests, the most probable causes of damage and deterioration in Brooks Aqueduct are:

1- In inland areas such as Brooks, where the winters are long and cold, the main durability issues with reinforced concrete are usually severe freeze-thaw damage of the concrete, concrete carbonation and corrosion of the steel reinforcing bars. These issues were not considered in the design of the aqueduct, because at that time, they were not known to be issues that needed to be considered.

2- Poor quality of concrete which is a result of the lack of knowledge about the effect of factors such as water-cement ratio, aggregate selection, curing, vibration, etc. on the quality and performance of the concrete at the time of construction of the aqueduct.

3- Poor workmanship in the placing of reinforcing bars, maintaining proper cover, concrete quality, etc. - again not known as issues that needed to be dealt with at the time of construction.

4- Lack of proper understanding of the behaviour of the concrete of the flume in tension and detailing of the reinforcement in different areas (adequate splice length, cover, etc.)

5- Lack of appropriate design of expansion joints to prevent water infiltration.

Given the factors mentioned above, the need to prioritize and plan for proper repair and restoration of the aqueduct is critical to prevent further damage. Because of the massive size of the aqueduct and the different areas that need to be addressed, and because of limitations in available conservation resources, it is essential that the structure be inspected and repaired frequently and that resources are allocated based on the importance and priority of the problem.

Acknowledgements. The authors gratefully acknowledge the support of Alberta Culture in providing access to the site and their archives. The University of Calgary provided substantial support through their computing resources and the Department of Civil Engineering, all of which is sincerely acknowledged. 


\section{REFERENCES}

[1] Manz, D.H. and Loov, R.E. Brooks Aqueduct. Canadian J. of Civil Engineering (1899), pp. 684-692.

[2] Finch, D. The Brooks Aqueduct, A Technological and Engineering History 1912-79. Environment Canada, Canadian Parks Services Report Series 360 (1988).

[3] Finch, D. Much Brain and Sinew: The Brooks Aqueduct Story. (1993), p. 50.

[4] Quinn Saretskey Structural Engineers Inc. Brooks Structural Assessment Report (2006).

[5] ISL Engineering. Brooks Aqueduct, Quantitative Engineering Assessment (2016).

[6] Dassault Systems. Abaqus 6.14 Analysis User's Guide (2014).

[7] Kmiecik, P. and Kamiński, M. Modelling of reinforced concrete structures and composite structures with concrete strength degradation taken into consideration. Archives of Civil and Mechanical Eng. (2011), vol. 11, no. 3, pp. 623-636.

[8] Sümer, Y. and Aktaş, M. Defining parameters for concrete damage plasticity model, Challange J. of Structurl Mechanics (2015), vol. 1, no. 3, pp. 149-155.

[9] Morgan, D.R. Compatibility of concrete repair materials and systems. Construction and Building Materials (1996). vol. 10, no. 1 SPEC. ISS., pp. 57-67. 